\title{
A rapid method of grading cataract in epidemiological studies and eye surveys
}

\author{
V MEHRA' AND D C MINASSIAN ${ }^{2}$ \\ From 'Chattisgarh Eye Hospital, Fafidih, Raipur, Madhya Pradesh, India, and the ${ }^{2}$ International Centre for \\ Eye Health, Institute of Ophthalmology, 27-29 Cayton Street, London EC1V 9EJ
}

SUMMARY A rapid method of grading clinically important central lens opacities has been developed for use in eye surveys and in epidemiological studies of cataract and has been field-tested in a specifically designed observer agreement study in a survey of a rural community in Central India. The grading method is based on simple measurement of the area of lens opacity that obscures the red reflex relative to the area of clear red reflex, as visualised through the undilated normal pupil. Good to almost perfect agreements were attained between two ophthalmologists and two trained ophthalmic assistants for overall grades of central lens opacity. Most disagreements were trivial in nature and were concerned with difficulties in distinguishing grade 0 from grade 1 , and with hazy appearance of the red reflex in high myopes and in cases of early nuclear sclerosis. Teaching materials including video tape and slides for training survey teams and other workers are in preparation

Prevalence surveys of blindness and eye disease require a reliable, repeatable, and rapid method for grading clinically important cataract, as do certain population based epidemiological studies of cataract, such as our programme of collaborative research into the incidence and causation of blinding cataract in Central India. A rapid method for grading central lens opacities has been developed and used in our collaborative studies.' The method focuses on grading lens opacities that are central, visible through the undilated pupil, and likely to interfere with vision. This paper reports on a study designed specifically for field assessment of the grading technique in a rural community in Central India.

\section{Material and methods}

A village community in the Arang block of Raipur District in Central India was surveyed by a team of four examiners and supporting auxiliaries. Immediately prior to the study the four examiners attended intensive sessions of training and standardisation exercises for a period of one week at the base hospital. Two ophthalmologists (VM and DCM) and two ophthalmic trained assistants (MT and SS) carried out the eye examinations and graded the lens Correspondence to D C Minassian. opacities. Visual acuities were measured by two auxiliaries who did not take part in the grading. Every eye was examined by all four examiners located at four separate stations in a darkened room in the village. Each examiner recorded his findings on separate record sheets which were later collated at the end of the field work. There were no consultations or further standardisation exercises during the field work.

\section{GRADING OF CATARACT}

The eye examinations were carried out with direct ophthalmoscopes fitted with new batteries at the beginning of the session. The red reflex was visualised through the undilated pupil with a direct ophthalmoscope set at $+2 \mathrm{D}$ and held at approximately $1 / 3 \mathrm{~m}$ from the eye. Opacities that partially obscured the red reflex were scrutinised from several angles of view to determine their location in relation to the lens. But the final assessment of the area of lenticular opacity was made by directing the light source away from the macula, towards the nasal portion of the retina, at an angle of approximately $25^{\circ}$ to the visual axis, in order to avoid excessive constriction of the pupil beyond the usual size in daylight. Opacities in the lens that disturbed the red reflex were distinguished from non-lenticular opacities 
Table 1 Rules for grading central lens opacities

\begin{tabular}{|c|c|}
\hline $\begin{array}{l}\text { Grade of } \\
\text { central lens } \\
\text { opacity }\end{array}$ & Criteria \\
\hline $\mathbf{0}$ & Clear red reflex, no opacities \\
\hline 1 & $\begin{array}{l}\text { Few small dot opacities in the lens appearing as tiny } \\
\text { scattered dark spots in the red reflex. Maximum area } \\
\text { occupied by the dots } 1 \mathrm{~mm}^{2}\end{array}$ \\
\hline $2 \mathrm{~A}$ & $\begin{array}{l}\text { Lens opacity obscuring part of red reflex. Area obscured } \\
\text { is smaller than area of clear red reflex }\end{array}$ \\
\hline 2B & $\begin{array}{l}\text { As } 2 \mathrm{~A} \text { but area obscured equal to or larger than area of } \\
\text { clear red reflex }\end{array}$ \\
\hline 3 & Lens opacity totally obscuring the red reflex \\
\hline 4 & Aphakia or displaced lens \\
\hline 5 & Unable to assess red reflex owing to corneal opacity etc. \\
\hline
\end{tabular}

and were graded according to the criteria set out in Table 1.

\section{ANALYSIS OF DATA}

The record sheets were collated and the data were entered into a portable microcomputer (Epson PX-8) at the end of the day. The data entry, tabulation, and statistical analysis software were developed at the ICEH specifically for this purpose.

The degrees of agreement between the examiners were measured by computing kappa statistics. These evaluate the amount of observed agreement beyond chance, relative to the maximum possible agreement over and above chance. ${ }^{2}$ Thus in most situations a kappa value of $0.81-1.0$ indicates almost perfect agreement, and kappa values of $0 \cdot 61-0.80$ suggest substantial agreement. ${ }^{3}$ Weighted kappa values were also computed by means of weights as suggested by Cicchetti and Allison. ${ }^{4}$
Table 2 Agreement between pairs of four examiners in grading central lens opacities. The table shows weighted and unweighted kappa values as measures of agreement

\begin{tabular}{lll}
\hline Examiners & \multicolumn{2}{l}{ Kappa values across all grades } \\
\cline { 2 - 3 } & Weighted & Unweighted $(S E=0.03)$ \\
\hline VM and DCM & 0.962 & 0.885 \\
VM and MT & 0.932 & 0.813 \\
VM and SS & 0.934 & 0.848 \\
DM and MT & 0.945 & 0.845 \\
DM and SS & 0.929 & 0.834 \\
MT and SS & 0.918 & 0.820 \\
\hline
\end{tabular}

VM and DCM are ophthalmologists, MT and SS are ophthalmic assistants.

\section{Results}

Each of the four examiners assessed and graded 246 eyes (123 persons), making a total of 984 examinations. The age distribution of the sample was somewhat skewed towards the older age groups, the youngest age being six years. The frequency of occurrence of the various grades of central lens opacities according to one of the ophthalmologists is shown in the marginal totals of Fig. 1. As expected, the eyes with cataract are over represented in the sample. The 'agreement cells' in Fig. 1 show the number of eyes that received identical grades from the two ophthalmologists. Disagreements were few and trivial in nature as shown in the body of Fig. 1 . The kappa statistic and its standard error indicate almost perfect overall agreement between the two ophthalmologists. The grade-specific agreements between the two ophthalmologists were also excel-
Fig. 1 Agreement between two examiners (ophthalmologists VM and $D C M$ ) in grading central lens opacities: the shaded agreement cells show number of eyes that were given identical grades by the two examiners.

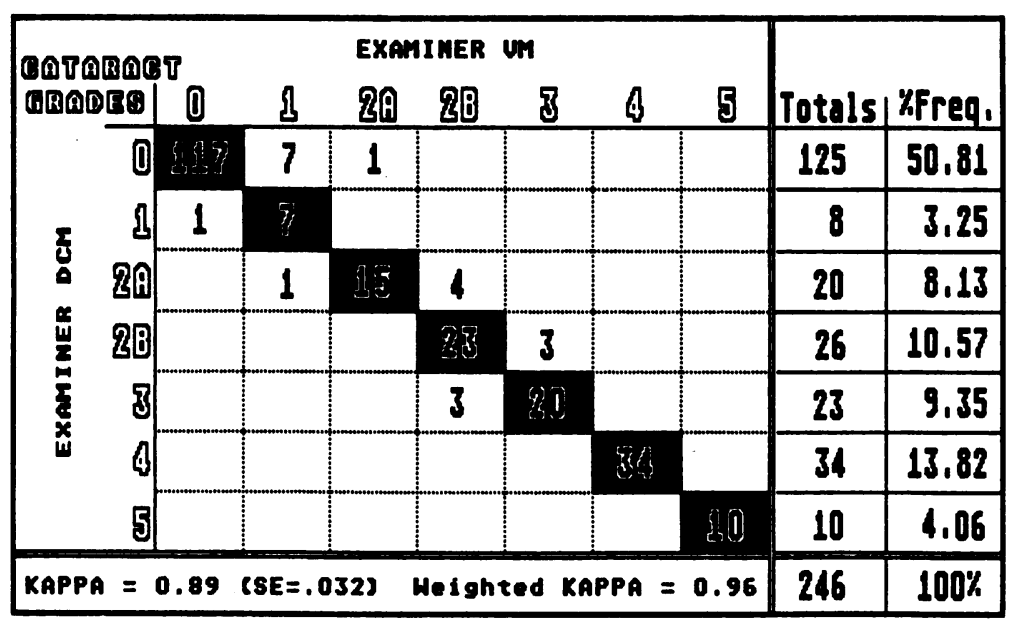


lent for all grades (except for grade 1), with kappa values ranging from $0 \cdot 8$ to $1 \cdot 0$. The kappa for grade 1 was lower at $0 \cdot 6$. However, the disagreements were clinically of little importance and arose largely from difficulties in distinguishing grade 0 from grade 1 .

The agreement between each ophthalmologist and each of the ophthalmic trained assistants was remarkably similar to that found between the two ophthalmologists. The relevant kappa values are reported in Table 2. The total time taken by the slowest examiner to grade 123 persons (246 eyes) and record the findings was about three hours, averaging at 1.5 minutes for grading one person.

\section{Discussion}

The survey study was designed specifically for assessment of the new grading method. The sample comprised a good mixture of various categories of central lens opacity and provided adequate numbers of eyes in each grade to enable assessment of gradespecific and overall degrees of agreement. The overrepresentation of cataract cases and aphakics was expected and hoped for, as no attempt had been made to examine every resident of the village or to take a random sample of a defined population.

The agreements attained were well above that generally considered satisfactory in prevalence surveys of eye disease and also in epidemiological

Table 3 Correlation of visual acuity with grades of central lens opacity. Aphakic eyes and those that could not be assessed for cataract (grade 5) are excluded

\begin{tabular}{|c|c|c|c|c|c|c|c|}
\hline \multirow[t]{2}{*}{$\begin{array}{l}\text { Visual } \\
\text { acuity }\end{array}$} & \multirow{2}{*}{$\begin{array}{l}\text { WHO* } \\
\text { category } \\
\text { of visual } \\
\text { impairment }\end{array}$} & \multicolumn{6}{|c|}{$\begin{array}{l}\text { Grades of cataract as graded by } \\
\text { ophthalmologist }(D C M)\end{array}$} \\
\hline & & 0 & 1 & $2 A$ & $2 B$ & 3 & Totals \\
\hline \multirow[t]{2}{*}{$6 / 6-6 / 9$} & 0 & 97 & 0 & 0 & 0 & 0 & 97 \\
\hline & & $100 \%$ & $0 \%$ & $0 \%$ & $0 \%$ & $0 \%$ & \\
\hline \multirow[t]{2}{*}{$6 / 12-6 / 18$} & 0 & 23 & 7 & 8 & 0 & 0 & 38 \\
\hline & & $61 \%$ & $18 \%$ & $21 \%$ & $0 \%$ & $0 \%$ & \\
\hline \multirow[t]{2}{*}{$6 / 24-6 / 60$} & 1 & $5 \dagger$ & 1 & 10 & 16 & 0 & 32 \\
\hline & & $16 \%$ & $3 \%$ & $31 \%$ & $50 \%$ & $0 \%$ & \\
\hline \multirow[t]{2}{*}{$5 / 60-3 / 60$} & 2 & 0 & 0 & 2 & 7 & 1 & 10 \\
\hline & & $0 \%$ & $0 \%$ & $20 \%$ & $70 \%$ & $10 \%$ & \\
\hline \multirow[t]{2}{*}{$2 / 60-1 / 60$} & 3 & 0 & 0 & 0 & 3 & 10 & 13 \\
\hline & & $0 \%$ & $0 \%$ & $0 \%$ & $23 \%$ & $77 \%$ & \\
\hline \multirow[t]{2}{*}{$<1 / 60$} & 4,5 & 0 & 0 & 0 & 0 & 12 & 12 \\
\hline & & $0 \%$ & $0 \%$ & $0 \%$ & $0 \%$ & $100 \%$ & \\
\hline Totals & & 125 & 8 & 20 & 26 & 23 & 202 \\
\hline
\end{tabular}

*The WHO categories of visual impairment are described in an offset publication No.54 available from the WHO, Geneva.

†Four of these were high myopes. studies where higher kappa values of more than 0.75 or so are demanded. The disagreement could be attributed to two main problems: distinction between grade 0 and grade 1 , and 'hazy' appearance of the red reflex in high myopes and cases of early nuclear sclerosis.

As expected, there was good correlation between the cataract grades and levels of visual impairment. The details are shown in Table 3 .

Finer grading of central and other lens opacities is necessary for follow-up studies or clinical trials that aim to quantify small changes in the area or density of opacification. However, clinical grading techniques are by and large inadequate for such studies, which require more objective methods of standardised documentation and quantitative image analysis techniques. ${ }^{5-8}$

Teaching materials including video tape, photographic slides, and prints of the various grades of central lens opacity for training survey teams and other workers are in preparation.

Our thanks to Mr Mohan Tiwari and Mr Shankar Sahu as two members of the examination team; Mr Santosh Agrawal for helping to organise the field work and providing a large darkened room in the village; other staff of Chattisgarh Eye Hospital as supporting members of the survey team.

This study was funded by the Chattisgarh Eye Hospital, Raipur, and the British Council for the Prevention of Blindness, UK.

\section{References}

1 Minassian DC, Mehra V, Jones BR. Dehydrational crises from severe diarrhoea or heatstroke and risk of cataract. Lancet 1984 ; i: 751-3.

2 Fleiss JL. Statistical methods for rates and proportions. 2nd ed. New York: Wiley, 1981.

3 Landis RJ, Koch GG. The measurement of observer agreement for categorical data. Biometrics 1977; 33: 159-74.

4 Cicchetti DV, Allison T. A new procedure for assessing reliability of scoring EEG sleep recordings. Am J EEG Technol 1971; 11: 101-9.

5 Hockwin O, Dragomirescu V, Laser H. Measurement of lens transparency or its disturbances by densitometric image analysis of Schleimpflug photographs. Graefes Arch Clin Exp Ophthalmol 1982; 219: 255-62.

6 Maclean H, Taylor CJ. An objective staging for cortical cataract in vivo aided by pattern-analysing computer. Exp Eye Res 1981; 33: 597-602.

7 Chylack LT, Cheng HM, White O. Retro-illumination and Topcon SL-45 photography of cataracts in vivo: a quantitative study of the variances of these techniques with computerized image analysis. Invest Ophthalmol Vis Sci 1984; 25 (ARVO abstr Sarasota Suppl): 270.

8 Cotlier E, Fagadau W, Cicchetti DV. Methods for evaluation of medical therapy of senile and diabetic cataracts. Trans Ophthalmol Soc UK 1982; 102: 416-22.

Accepted for publication 10 September 1987. 